\title{
Improving the safety of nasogastric tube insertion by the "SORT maneuver" during the novel coronavirus pandemic (COVID-19)
}

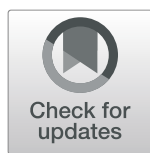

Mahdi Najafi, ${ }^{1}$ (10

Keywords: Nasogastric tube, Insertion, Complications, Outbreak, COVID-19, Infection prevention

The "SORT maneuver" (sniffing position, NGT orientation, contralateral rotation, and twisting movement) was introduced in 2016 to ease nasogastric intubation for unconscious patients in operating theatre and critical care setting [1]. This technique is aimed at a safe practice without using equipment. Safety has never been more important than the current outbreak of SARS-CoV-2 infection. SORT maneuver can be of benefit for both the healthcare workers and the patients who are struggling with coronavirus during this pandemic.

From the practitioner's point of view, any procedure which is done in close contact with an infected patient's airway carries a higher risk of respiratory infection transmission which may not get totally eliminated after tracheal intubation $[2,3]$. With regards to NGT intubation, this is supported by updated guidelines that consider placement of any enteral access device as an aerosolgenerating procedure [4]. Moreover, NGT insertion may expose healthcare workers to infectious saliva of patients with coronavirus [5]. Feasibility of NGT insertion and the number of attempts for intubation matter as well, when it comes to a safe bedside practice. The first clinical trial reporting successful employment of SORT maneuver for NGT insertion in unconscious patients admitted to intensive care unit was just recently published

Correspondence: mahdi.najafi@uwo.ca; mahdinajafikoo@gmail.com 'Schulich School of Medicine \& Dentistry, Western University, Room M402, Medical Sciences Building, 1151 Richmond St, N6A 3K7 London, Ontario, Canada

${ }^{2}$ Department of Anesthesiology, Tehran Heart Center, Tehran University of Medical Sciences, Tehran, Iran with promising results [6]. This study showed that ease of insertion was considerably greater and success rate was much higher for SORT maneuver than the other conventional technique of neck flexion and lateral pressure. The observation that SORT was "easy to learn by unskilled providers" is an asset in a crisis like COVID-19 outbreak [7]. Also, compared to this technique which is based on anatomical approach, NGT insertion using laryngoscope and/or Magill forceps can even increase the risk substantially as it is more invasive and requires closer proximity to the airway [8]. Although trachea is intubated, security of airway is not guaranteed at least in circumstances such as ventilation at high inspiratory pressure, sputum induction, and manual ventilation especially with undersized or uncuffed tracheal and tracheostomy tubes [9].

On the other hand, the management of the patients' coexisting problems such as cardiovascular disease and hemodynamic instability is a challenge during NGT intubation. Pharyngeal manipulation during NGT insertion is a potential treat for cardiac patients by increasing demand especially in hypertensive patients with uncontrolled blood pressure. These patients are the most vulnerable group to higher incidence of severe illness and worse outcome in COVID-19 as well [10, 11]. Smooth process of NGT insertion without equipment using SORT maneuver, is capable of preventing from brisk hemodynamic response and its adverse effects [12]. If this is also of benefit for infected patients with coronavirus, is a question to be addressed. Using paralyzing drugs whenever is indicated, mitigates patient's reactions 
and probably can reduce the risk [3]. However, unlike the operating theatre, we seldom use these agents in intensive care unit.

NGT tube insertion in intubated patient is a quite common procedure in operation theatre and intensive care settings. In patients with COVID-19 infection, SORT maneuver may protect both practitioners and patients from further avoidable hazards. I would encourage my colleagues to verify these proposals in their daily practice and by further investigations through clinical trials.

\section{Abbreviations}

COVID-19: Coronavirus disease 2019; NGT: Nasogastric tube

\section{Acknowledgements}

Not applicable.

\section{Authors' contributions}

M.N. designed and wrote this article. The author read and approved the final manuscript.

\section{Authors' information}

Dr. Najafi is trained in anesthesiology, intensive care and cardiac anesthesia. He is associate professor of anesthesiology at Tehran Heart Center, affiliated to Tehran University of Medical Sciences and adjunct professor at Schulich School of Medicine, Western University.

\section{Funding}

No funding

\section{Availability of data and materials}

Data sharing does not apply to this article as no datasets were generated or analyzed during the current study.

\section{Ethics approval and consent to participate}

Institutional review board is not required for this type of articles.

\section{Consent for publication}

Not applicable.

\section{Competing interests}

The author declares that he has no conflict of interest.

Received: 7 December 2020 Accepted: 9 December 2020

Published online: 06 January 2021

\section{References}

1. Najafi M, Golzari S. SORT maneuver for nasogastric tube insertion. Anaesthesia. 2016;71:351-1.

2. Public Health England. COVID-19: infection prevention and control guidance. 2020. https://www.gov.uk/government/publications/wuhannovel-coronavirus-infection-prevention-and-control Accessed December 7, 2020.

3. Cook TM, El-Boghdadly K, McGuire B, McNarry AF, Patel A, Higgs A. Consensus guidelines for managing the airway in patients with COVID-19: Guidelines from the Difficult Airway Society, the Association of Anaesthetists the Intensive Care Society, the Faculty of Intensive Care Medicine and the Royal College of Anaesthetists. Anaesthesia. 2020;75:785-99.

4. Martindale R, Patel JJ, Taylor B, Warner M, McClave SA. Nutrition therapy in the patient with COVID-19 disease requiring ICU care. American Society for Parenteral and Enteral Nutrition, Society of Critical Care Medicine. Available at: https://www.sccm.org/getattachment/Disaster/Nutrition-Therapy-COVID-1 9-SCCM-ASPEN.pdf?lang=en-US. Accessed December 1, 2020.

5. Sturrock BR, Fanning SJ, Khan M, Sajid MS. Should nasogastric tube insertion during the COVID-19 pandemic be considered as an aerosol-generating procedure? Br J Hosp Med. 2020;81:6.
6. Sanaie S, Mirzalou N, Shadvar K, Golzari SE, Soleimanpour H, Shamekh A, Bettampadi D, Safiri S, Mahmoodpoor A. A comparison of nasogastric tube insertion by SORT maneuver (sniffing position, NGT orientation, contralateral rotation, and twisting movement) versus neck flexion lateral pressure in critically ill patients admitted to ICU: a prospective randomized clinical trial. Ann Intensive Care. 2020:10:79

7. Najafi M. SORT maneuver: ease and safety for the practitioner and the patient. Ann Intensive Care. 2020;10:160.

8. Sanaie S, Mahmoodpoor A, Najafi M. Nasogastric tube insertion in anaesthetized patients: a comprehensive review. Anaesth Intensive Ther. 2017:49:57-65.

9. Weissman DN, de Perio MA, Radonovich LJ. COVID-19 and Risks Posed to Personnel During Endotracheal Intubation. JAMA. 2020;323(20):2027-8. doi: https://doi.org/10.1001/jama.2020.6627.

10. Schiffrin EL, Flack JM, Ito S, Muntner P, Webb RC. Hypertension and COVID19. Am J Hypertens. 2020;33:373-4. doi:https://doi.org/10.1093/ajh/hpaa057.

11. Cummings MJ, Baldwin MR, Abrams D, Jacobson SD, Meyer BJ, Balough EM, Aaron JG, Claassen J, Rabbani LE, Hastie J, Hochman BR. Epidemiology, clinical course, and outcomes of critically ill adults with COVID-19 in New York City: a prospective cohort study. The Lancet. 2020;395:1763-70.

12. Najafi M. Nasogastric tube insertion easily done: the SORT maneuver. Indian Crit Care Med. 2016:20:492-3.

\section{Publisher's Note}

Springer Nature remains neutral with regard to jurisdictional claims in published maps and institutional affiliations.

\section{Ready to submit your research? Choose BMC and benefit from:}

- fast, convenient online submission

- thorough peer review by experienced researchers in your field

- rapid publication on acceptance

- support for research data, including large and complex data types

- gold Open Access which fosters wider collaboration and increased citations

- maximum visibility for your research: over $100 \mathrm{M}$ website views per year

At $\mathrm{BMC}$, research is always in progress.

Learn more biomedcentral.com/submissions 